\title{
OUTRAS METODOLOGIAS E OUTRAS EPISTEMOLOGIAS: PESQUISAS COM CURRÍCULOS A CAMINHO DE BACURAU
}

\author{
Maria Luiza SÜSSEKIND - UNIRIO/FAPERJ/CNPq
}

Ruth PAVAN/UCDB/CNPq

O dossiê Outras epistemologias e metodologias nas investigações sobre currículo apresenta um pequeno leque de produções no campo do currículo, demonstrando as potencialidades de pesquisas em que se opta por percorrer caminhos outros. Nossa pretensão na proposição desse dossiê foi, como nos diz Spivak (2010, p. 70), romper com a "violência epistêmica", reconhecendo que "o sujeito subalterno colonizado é irremediavelmente heterogêneo." (SPIVAK, 2010, p.70, grifo da autora). Essa heterogeneidade tem sido criminalizada por um movimento ultraconservador; sobretudo, têm sido criminalizados os grupos étnico-raciais, especialmente as populações indígena e negra, tão presentes na América Latina, e os grupos LGBT+.

Portanto, trazer para o tema de um número especial de revista renomada como a Teias, proposto pela ABdC (Associação Brasileira de Currículo), o debate focado nos currículos em outras epistemologias e outras metodologias é a tentativa de estancar/suspender o momento histórico em que vivemos, marcado pelo racismo, que "[...] é acima de tudo uma tecnologia destinada a permitir o exercício do biopoder, 'este velho direito soberano de matar'.” (MBEMBE, 2018, p.18). A propósito, podemos enumerar tristes e recentes acontecimentos que ratificam o que diz o autor: "na economia do biopoder, a função do racismo é regular a distribuição da morte e tornar possíveis as funções assassinas do Estado.” (MBEMBE, 2018, p.18).

Para caminhar com Mbembe (2018) e o que ele, e as autoras e autores desse dossiê nos dizem, podemos lembrar do filme Bacurau, quando um personagem, de fora da cidade, pergunta: "Quem nasce em Bacurau é o quê?”. Uma criança do local responde: “É gente!”.

A resposta da criança, embora revele uma obviedade, nas circunstâncias nas quais vivemos hoje parece não ser tão obvia assim. Precisamos lembrar que quem nasce em Bacurau é gente, quem nasce na favela é gente, quem nasce nas comunidades indígenas é gente, quem nasce em comunidades quilombolas é gente, quem não segue a heteronormatividade é gente, quem nasce na rua é gente, quem nasce sem terra é gente, quem não tem emprego é gente. É gente que resiste, que forja outros modos de ser, conhecer, conviver e estar no mundo. É gente que sempre enfrenta o poder colonizador, ainda que em condições abissais (SANTOS, 2010). Quando parece não existirem condições para 
enfrentar o poder colonizador, hegemônico e opressor, a gente usa o silêncio como afronta, finge-se de invisível para desafiar a ordem estabelecida, cria fissuras na lógica que fortalece os processos colonizadores. Bacuralizar o currículo é descolonizar. Descolonizamos o currículo porque inventamos, porque criamos outras coisas, porque não admiramos o colonizador, porque nos rebelamos em relação à epistemologia colonial. Descolonizamos porque rejeitamos e lutamos contra a linha abissal do conhecimento e somos contra o fascismo epistemológico. Descolonizamos porque afirmamos a existência da pluralidade epistemológica e metodológica.

O que podem outras epistemologias e metodologias? O que podem outros currículos? São algumas reflexões que a leitura dos artigos, da entrevista e da resenha que compõem este dossiê nos proporciona. Os estudos curriculares no Brasil são um campo intelectualmente vibrante e impressionante, que exibirá uma forte presença em todo o mundo. (...) Os estudos curriculares devem permanecer atentos ao passado, reavaliando constantemente a importância e o significado do trabalho realizado anteriormente1 (KUMAR, 2011, p. 41)

As pesquisas presentes neste dossiê, cada uma com suas ênfases, propõem rupturas com a epistemologia hegemônica do currículo, marcadamente moderna-branca-masculina-euro-usacêntrica (WALSH, 2012). Novamente, trazemos Mbembe (2018) para dizer que este dossiê visa a desafiar "a ideia de que, necessariamente, a racionalidade da vida passe pela morte do outro" (p.20), seja ela epistêmica, simbólica, física, ou qualquer modo de subalternização do outro. O dossiê é um sim à vida, à criação, à imaginação, à transgressão, à diversidade epistemológica e metodológica.

De Bacurau, falamos de um campo-palimpsesto que sempre se fez dissensuoso e glocal, marcando sua existência pela tradução diatópica e cultural. Por isso, do lado de cá, perguntamos como a personagem em Bacurau se "você quer viver, ou morrer?" (2019) e convidamos à vida que flui, multiplica sentidos, enuncia, transgride e hibridiza, deixando o mundo pelo avesso. Descentramentos nas teorias curriculares provocando deslocamentos epistêmicos desenham outros mapas, nos levando ao fim do mapa. O mapa termina em Bacurau? Os mapas acabam nos currículos?

Como apresentadoras desse número, nos vimos diante da necessidade de marcar as presenças de teorias que formataram o campo, como também daquelas que abalroaram seus mapas teóricos, a caminho das fronteiras, dos territórios desconhecidos, explorando cada possibilidade, curriculando no ritmo de Bacurau. Sendo um campo de disputas densas e inovadoras, reconhecemos que

\footnotetext{
${ }^{1}$ No original Curriculum studies in brazil is an intellectually vibrant and impressive field, one that will exhibit a strong presence worldwide. (...) curriculum studies must remain attentive to the past, constantly reevaluating the significance and meaning of work conducted earlier. Tradução nossa.
} 
Os debates atuais trazem marcas da forte presença da noção de habitus de Bourdieu (2003); da epistemologia do cotidiano de Michel de Certeau (1994); do paradigma da complexidade de Edgar Morin; das epistemologias do oprimido, pós-coloniais e do Sul (Nunes, 2010; Santos, 2010) e, das discussões tanto críticas quanto pós-modernas sobre política. Trazem mais do conceito de identidade do que do etnicidade de Stuart Hall (1997); além de importantes debates sobre espaço e tempo que reconhecem as fronteiras, seus entrelugares e híbridos de Bhabha (1998), como explora Carlos Eduardo Ferraço (Pinar, 2011). Além disso, leituras originais que desdobram a arquitetura do self de Derrida e exploram os rizomas curriculares a partir de Deleuze; bem como a ontologia de Maffesoli estão permeando debates, nos quais Pinar, também destaca a extrema sofisticação teórica presente na noção de currículo como desfiguração de Antônio Carlos Amorim (Pinar, 2011: 55-69). Essas leituras profundamente questionadoras das referências e a criatividade em produzir múltiplos sentidos de currículo e formas de fazer pesquisa em currículo proliferam em muitas teorias nativas, enriquecendo ainda mais a nossa diversidade epistemológica (Pinar, 2011). (OLIVEIRA, SUSSEKIND, 2017, p. 15)

Em leque, sem a pretensão de percorrer a história do campo ou de registrar os principais debates da atualidade, apresentamos um caminho. Caminho que nos leva ao sertão, ao estranho, ao outro. Numa composição de escritas curriculares animadas pelo cenário anticolonial de Bacurau, apresentamos, abaixo, os resumos dos artigos e da resenha que compõem o dossiê, que ainda conta com entrevista feita por Rafael Marques Goncalves à Nilda Alves. Voz que lembra que, no campo, “temos insistido em 'pensar além': entendemos que todos os momentos de crise, como o que vivemos agudamente no presente - exigem duas ações complementares: a resistência e a criação".

Traduzido para este número, o artigo Descolonização e a Pedagogia da Solidariedade, de autoria de Rubén A. Gaztambide-Fernández, traz os efeitos do processo de colonização que vivemos. Também faz uma chamada aos educadores para que sejam protagonistas de novas formas de encontros, que resistam à colonialidade. Para isso, o autor aponta a necessidade de repensar o humano e de recentralizar a diferença. Além de uma genealogia do conceito de solidariedade, o autor apresenta uma Pedagogia da Solidariedade, que criativamente se compromete com o processo de descolonização.

$\mathrm{O}$ artigo intitulado Bichas pretas e negões: seus fazeres curriculares em escolas das periferias, de autoria de Marcio Rodrigo Vale Caetano, Tarciso Manfrenatti de Souza Teixeira e Paulo Melgaço da Silva Junior, por meio de uma autoetnografia, faz um deslocamento da perspectiva hegemônica do homem-branco-humano. Além disso, tumultua a masculinidade negra. Para isso, traz as bichas pretas, colocadas à margem das margens da periferia. $\mathrm{O}$ artigo discute a interseccionalidade raça, gênero e classe em um contexto de colonialidade. Como afirmam os autores, a bicha está no meio de um fogo cruzado, ela é máquina de guerra, é um devir que desestabiliza e interroga. O artigo é relevante para o campo do currículo, pois, ao discutir as bichas pretas e negões, rompe não só com 
uma epistemologia hegemonicamente branca, mas também com a naturalização da masculinidade negra.

O artigo Corpo-território como argumento curricular de resistência, de autoria de Ana Angelita da Rocha, apresenta um convite para pensarmos a relação corpo-território e incorporarmos outras linguagens e estéticas do currículo, construindo uma outra discussão da geopolítica curricular. Convida-nos a reinventar as escolas e os currículos, produzindo um currículo descolonizado, um currículo que seja, sobretudo, para os vulneráveis, lugar de encontro.

$\mathrm{O}$ artigo de Regina Lucia Fernandes Albuquerque, intitulado Interculturalidade na Educação Infantil: a matriz curricular das relações étnico-raciais, traz uma discussão calcada em epistemologias outras, com ênfase na interculturalidade e na matriz teórica pós-colonial. A pesquisa descreve processos intraescolares que se aproximam de uma perspectiva intercultural e ressalta-a como caminho para um currículo articulado com a diversidade presente na escola.

O artigo Assim como viver, resistir não é preciso? Pós-utopia e currículo em tempos sombrios, de Maria Inez da Silva de Souza Carvalho e Julio Bispo dos Santos Junior, fruto de uma pesquisa bibliográfica, discute as tensões que circundam os sentidos de utopia e as possibilidades para pensar o currículo em uma perspectiva geo-histórica. Além disso, o texto afirma o imperativo de que resistir é preciso, com o qual, nós, organizadoras, concordamos e reiteramos. Por fim, os autores anunciam que a pesquisa prossegue, afastando-se de um currículo iluminista, para pensar um currículo pós-utopia.

O artigo Alteridade nos currículos de matemática: a inversão do vetor e a ação dos atores na escola, dos autores Júlio César Augusto do Valle e Andréia Lunkes Conrado, parte de uma pesquisa com a Educação de Jovens e Adultos, apresenta o inexorável reconhecimento da alteridade, em especial da alteridade diversa. Isso, segundo os autores, contribui para pensarmos o currículo da matemática não em uma perspectiva técnica, mas política. Ou seja, no artigo, está em jogo outra epistemologia, não a naturalizada em um currículo que desconhece a produção dos diferentes conhecimentos que circulam na escola, mas a de um currículo que cria uma escola viva.

O artigo Cartografias de pesquisa e currículos que movimentam os corpos na educação infantil, de autoria de Ana Cláudia Santiago Zouain e Larissa Ferreira Rodrigues Gomes, por meio de uma pesquisa cartográfica produzida coletivamente na Educação Infantil, focando as imagens de currículo que a escola tem trabalhado. A pesquisa não pretendeu defender verdades, mas acompanhar os movimentos do cotidiano escolar. As autoras afirmam que se distanciam de currículos petrificados e apostam em currículos como acontecimento, o que significa uma ruptura com a prescrição e uma 
atenção ao que se insurge nos cotidianos escolares. A pesquisa, mediante experimentações infantis com o cinema, constrói outros possíveis no currículo escolar.

O artigo Desafios da integração curricular: a prática interdisciplinar nos espaços dos Seminários Integrados, de Tábata Valesca Corrêa e Luís Armando Gandin, apresenta uma discussão com base nas Teorias Educacionais Críticas e na Sociologia da Educação para analisar uma prática curricular no Ensino Médio Politécnico. Os autores apontam a predominância da hegemonia disciplinar e as dificuldades da construção de um currículo que privilegie a integração curricular e a interdisciplinaridade, mostrando que a formação dos professores ainda é um dos limites de sua implementação e que a cultura escolar contribui para a cristalização do currículo disciplinar, que é hegemônico.

O artigo intitulado Análise de prosa enredada na pesquisa com os cotidianos: um jeito de ver o currículo e dizer, dos autores Valdriano Ferreira do Nascimento, Isabel Maria de Sabino Farias e Evódio Maurício Oliveira Ramos, traz uma pesquisa que utiliza o método de Análise de Prosa Enredado (APE). Esse método, por ser multidimensional, possibilita compreender diferentes perspectivas da experiência vivida. A pesquisa de campo ocorreu com professores e alunos de um curso de Pedagogia, e a abordagem metodológica mostrou-se adequada ao tipo de estudo proposto.

\section{O artigo Conversas entre professores: produção de currículos nos processos de formação} contínua, das autoras Graça Reis e Marina Santos Nunes de Campos, é resultado de pesquisa que ressalta a importância das narrativas docentes para o processo de formação continuada. Também explicita a importância da partilha nas rodas de conversas entre os professores do Ensino Fundamental como algo que produz conhecimentos, o que parece mais potente para o currículo escolar do que as propostas de formações continuadas de caráter oficial. Essa perspectiva adotada na pesquisa explicita a autoria e a produção do conhecimento dos professores, rompendo com uma visão colonizadora do professor, compreendido como aquele que somente é capaz de executar o que outro pensou.

Por fim, o artigo Saberes da biodiversidade: perspectivas decoloniais no currículo do ensino de biologia, de autoria de Marco Antonio Leandro Barzano e André Carneiro Melo trazem um diálogo com aquilo que denominam "currículo das margens", quando se refere a sujeitos forçadamente invisibilizados que produzem e são produzidos por estes currículos. Pretende-se aqui debruçar na tríade temática: “currículo, relações étnico-raciais e educação ambiental”, temas que consideramos importantes na formação do(a) professor(a) de biologia. É neste contexto que, ao abordar sobre os saberes da biodiversidade em uma comunidade quilombola, emergem os saberes nascidos da luta que nos mostram a potência do movimento negro educador e, dessa maneira, uma 
efetiva contribuição para descolonizar os currículos de ciências/biologia e construir possibilidades para a insurgência de uma pedagogia decolonial.

Ainda trazemos, na resenha de Liz Janson, o exame de como a obra Epistemologias Curriculares de João Paraskeva aprofunda seu trabalho anterior sobre a Teoria dos Currículos Itinerantes (TIC) e discute como isso pode ser visto na sala de aula de educação pública dos EUA. Analisa como os meandros das TIC permitem que os educadores lutem por uma pedagogia justa, criando espaços de empoderamento para os jovens e descolonizando o Currículo; e, como a padronização do currículo dos EUA pode ser vista como uma anti-TIC. Essa análise reflete a necessidade de lutar pela justiça social e cognitiva por meio de uma pedagogia justa da esperança. Fechando o conjunto de escritas, a entrevista com Nilda, sublinha os movimentos epistêmicosteóricos-metodológicos que densificam e politizam o campo no Brasil e, na direção da descolonização, tematizam esse úmero especial.

Esse mundo tá virado de cabeça prá baixo. ${ }^{2}$

Enfim, pensar com Bacurau é seguir na direção do Sul epistemológico e descolonizar. É admitir a copresença radical que compreende a simultaneidade e contemporaneidade, abandonando a ideia de uma existência de evolução de práticas, culturas e da própria humanidade através do tempo. Isso envolve descentrar, descolonizar o saber e o poder. Envolve reconhecer que há no mundo uma enorme diversidade epistemológica e que não há a possibilidade de uma epistemologia geral (SANTOS, 2010) construindo, cotidianamente, os muitos sentidos de currículos e descolonização, num políssono, como lemos nesse numero especial ABdC/Teias. Descentrar as metodologias e epistemologias hegemônicas é pensar com as redes de forma historicizada e permeada do reconhecimento das múltiplas violências, resistências, criações em subjetividades. E, temos deslocado conhecimentos curriculares... Assim, deslocar é curricular, é bacurar.

Desafios imensos, como analisar os quase quarenta excelentes artigos enviados, é o desafio de permanecer lutando, e vivendo. Para isso precisamos adiar o fim do mundo e defender tantas e tantos oprimidos, que são também as pesquisadoras e pesquisadores, as professoras e professores, alvos das intermináveis guerras coloniais (KRENAK, 2019) que hoje se definem também antiintelectuais. Densamente intelectualizado, cada vez mais descolonizador, apresentamos um leque dos debates do campo do currículo sobre outras metodologias e epistemologias por meio dos artigos aqui publicados. Um campo polissêmico e híbrido, que, nas palavras acuradas de Pinar (2011, p. 201)

\footnotetext{
${ }^{2}$ MENDONÇA FILHO, K., DORNELES, J. Bacurau. 2019.
} 
anuncia que "apesar do peso do passado e do poder do presente, realizações inovadoras são possíveis" (PINAR, 2016, p. 36). Nas dobras de Bacurau, convidamos leitoras, leitores ao percurso, e, pedimos que, se vier, venha em paz.

\section{Referências}

KRENAK, A. Ideias para adiar o fim do mundo. $1^{\text {a }}$ ed. São Paulo: Companhia das Letras, 2019.

KUMAR, A. curriculum studies in brazil: an overview. In: PINAR, William Frederick. Curriculum studies in Brazil: intellectual histories, present circumstances. New York: Palgrave Macmillan, 2011.

MBEMBE, Achile. Necropolítica: Biopoder, soberania, estado de exceção, política da morte. São Paulo: n-1 edições, 2018.

OLIVEIRA, INÊS BARBOSA DE and SUSSEKIND, MARIA LUIZA. Das teorias críticas às críticas das teorias: um estudo indiciário sobre a conformação dos debates no campo curricular no Brasil. Rev. Bras. Educ. [online]. 2017, vol.22, n.71, e227157. Epub Oct 09, 2017. ISSN 1413-2478. http://dx.doi.org/10.1590/s1413-24782017227157.

PINAR, W. In: LOPES, A. C., MACEDO, E. (org) Estudos Curriculares: ensaios selecionados. Cortez, Editora, São Paulo, 2016.

PINAR, W. F. Curriculum studies in Brazil: Four concepts. In: PINAR, William Frederick. Curriculum studies in Brazil: intellectual histories, present circumstances. New York: Palgrave Macmillan, 2011.

WALSH, Catherine. Interculturalidad y (de)colonialidad: Perspectivas críticas y políticas. Visão Global, Joaçaba - SC, v. 15, no 1-2, p. 61-74, jan./dez. 2012.

SANTOS, B. S. Para além do pensamento abissal: das linhas globais a uma ecologia de saberes. In: SANTOS, B. S.; MENESES, Maria P. Epistemologias do Sul. Edições Almedina S/A: Coimbra. 2010. Cáp. 1, p. 31-83.

SPIVAK, Gayatri Chakravorty. Pode o subalterno falar? Belo Horizonte: Editora UFMG, 2010.

${ }^{3}$ MENDONÇA FILHO, K., DORNELES, J. Bacurau. 2019. 